\title{
SOBRE O FENÔMENO DA TÉCNICA PLANETÁRIA: UMA REFLEXÃO INTRODUTÓRIA
}

\author{
On the phenomenon of planetary technique: An introductory reflection
}

Wanderley José Ferreira Jr

UFG

Resumo: Explicita-se alguns aspectos fundamentais do pensamento heideggeriano tomando como fio condutor o aparecimento da questão da Técnica em diferentes momentos desse pensamento. Para além de uma abordagem antropológico-instrumental do fenômeno da técnica e seus efeitos práticos, vamos tentar compreendê-la como princípio metafísico que determina hoje todas as formas do homem relacionar com outros e com a natureza. Procura-se ainda compreender qual a natureza do pensamento apto a colocar em questão essa essência não técnica e ainda impensada da Técnica.

Palavras-chave: Filosofia - Ciência - Tecnologia - Metafísica

Abstract: It explains some fundamental aspects of Heideggerian thought taking as a guiding thread the appearance of the question of the Technique at different moments of this thought. Beyond from an anthropological-instrumental approach to the phenomenon of technique and its practical effects, we will try to understand it as a metaphysical principle that determines all forms of man today to relate to others and to nature. It is also sought to understand the nature of thinking capable of calling into question this non-technical and still unthought essence of Technique.

Keywords: Philosophy - Science - Technology - Metaphysics

\section{Introdução}

Minha intenção é conduzi-los por algumas trilhas abertas pelo pensar heideggeriano tomando como fio condutor o aparecimento da questão da Técnica em diferentes momentos desse pensamento. Não nos interessa aqui estabelecer um confronto entre Heidegger e seus diversos críticos, particularmente no que se refere à questão da técnica. Evitaremos também as polêmicas acerca do engajamento político do filósofo e das possíveis repercussões ético-políticas de suas reflexões sobre a 
técnica moderna ${ }^{1}$. Mesmos os críticos reconhecem que é bastante original a concepção de Heidegger sobre o fenômeno da técnica. Uma concepção que rompe os limites da concepção antropológico instrumental da mesma, considerando-a um princípio epocal $^{2}$ que condiciona uma determinada concepção de sujeito humano, da totalidade do ente e da verdade, além de marcar o acabamento/fim da filosofia como metafísica.

Para além de uma mera condenação moral da técnica e seus efeitos, Heidegger coloca-nos questões, tarefas, evitando propor uma política, uma ética ou um desvio pela poesia como forma de superação da era da técnica. Assim, tomando como fio condutor a questão da técnica, delimitamos no vasto conjunto da obra heideggeriana uma bibliografia básica que reúne alguns textos nos quais tal questão é abordada da forma mais "clara" possível. Desde já convidamos os leitores a ouvirem e a pensarem a expressão "questão da técnica" da mesma forma que Heidegger nos convida para ouvir e pensar a "Seinsfrage" (A questão do Ser), ou seja, no duplo sentido do genitivo objetivo e subjetivo. A questão da técnica não é apenas uma questão que tem a técnica como objeto, mas é a própria técnica, enquanto manifestação epocal do próprio Ser, que interroga a si mesma nessa questão.

Em um primeiro momento vamos expor, ainda que de forma esquemática, como e quando a técnica passou a ser pensada por Heidegger a partir de seu encontro com a obra de Ernst Jünger. Em seguida, rompendo com uma abordagem antropológico-instrumental do fenômeno da técnica, vamos expor os aspectos básicos da leitura que Heidegger faz da essência da técnica e do perigo que ali se aloja. Procura-se ainda compreender qual a natureza desse pensar que Heidegger chama de

\footnotetext{
${ }^{1}$ Sobre o tema - técnica e política em Heidegger, remeto o leitor às reflexões de Silvio Vietta presentes em sua obra Heideggers Kritik am Natiosozilismus und an der Technik. Para Vietta, uma análise escrupulosa dos textos demonstra que existiria uma implicação entre o aprofundamento da reflexão sobre a técnica moderna e a história da ciência e o distanciamento crítico de Heidegger do nacionalsocialismo, que não passaria no plano político de uma forma aberrante do gigantismo e da violência explicita ou implícita do aparato técnico-científico que estende seu domínio por todo planeta. Cf. VIETTA, Silvio. Heideggers kritik am Natiosozilismus und na der Technik. Tubingen: Niemeyer, 1989.

2 Princípio Epocal: Noções fundamentais da linguagem metafísica que determinam o modo de dizer e pensar o Ser em determinada época da Metafísica(Eidós, Energéia, Deus, Cogito, Sujeito Transcendental, Sujeito Absoluto, Vida, vontade de potência, e a Técnica). Ao destruir a história da Metafísica ocidental, Heidegger procura desvelar o que permaneceu não-dito e impensado nesses princípios epocais.
} 
originário e que teria como tarefa no fim da filosofia justamente pensar a essência não técnica da técnica.

Mas quando a questão da técnica teria surgido de forma explícita no percurso do pensamento heideggeriano?

\section{O surgimento da questão da técnica no percurso do pensamento heideggeriano}

Se reportarmos à analítica existencial de Ser e Tempo (1927), mais precisamente as descrições fenomenológicas dos entes intramundanos em sua manualidade/instrumentalidade (Zeuglichkeit) e do mundo em sua mundanidade (Weltlichkeit), observaremos que a questão da técnica não foi explicitamente tematizada em tal obra. (Cf. HEIDEGGER, § 14 a §18; §22 a §24, 1988). No mundo constituído pelo homem enquanto ser-aí (Dasein), seu ocupar, seu ter que fazer algo é um deixar-ser, deixar-surgir o ente em um mundo já previamente descoberto, que em nada se assemelharia a intervenção provocadora que a técnica promove no mundo dos entes. Para questionar a essência ainda impensada da técnica moderna, Heidegger viu-se obrigado a ultrapassar os limites da analítica existencial de Ser e Tempo.

É certo que as "destruições" da noção de mundo em Descartes e da noção tradicional de Verdade (§44) em Ser e Tempo, podem ser consideradas antecipações das tentativas posteriores do pensador de "destruir" o modo de presentificação imposto pela técnica via pensamento calculador. Isso porque a técnica é considerada por Heidegger como fase terminal da metafísica que consuma a metafísica do sujeito, que começa com o sujeito puro cartesiano, passa pelo sujeito transcendental kantiano e consumando-se no além-do-homem de Nietzsche. As épocas da metafísica corresponderiam a uma determinada concepção de verdade e experiência da totalidade do ente. Nesse sentido, a técnica como fase terminal da metafísica/filosofia impõe-nos uma determinada concepção de verdade e experiência das coisas transformadas em objetos redutíveis ao cálculo. Heidegger percebe que a compreensão do fenômeno da técnica exigiria uma interpretação/rememoração do Ser e de sua verdade que se desdobra ao longo da história da metafísica. Daí a necessidade de rememorar alguns momentos fundamentais da história da metafísica 
na tentativa de compreender como tais momentos e posições metafísicas teriam conduzido à dominação incondicional da técnica moderna sobre a totalidade do ente.

O fato é que entre as reais motivações que levaram Heidegger a colocar em questão a técnica moderna estariam algumas ideias centrais de Ernst Jünger defendidas em obras como Mobilização total (Totale Mobilmachung) (1930) e O trabalhador (Der Arbeiter) (1932). Em tais obras a técnica é concebida à luz da Vontade de Poder nietzschiana corporificada na figura do trabalhador. O contato com Jünger teria assim inspirado o filósofo a pensar um dos fenômeno que hoje atinge dimensões planetárias - a mobilização total do mundo pela técnica. (Cf. JÜNGER, 1989)

Em seu Discurso de Reitorado - A autoafirmação da Universidade alemã (Die Selbstbehauptung der Deutschen Universität) (1933), já sob influência de Jünger, Heidegger fala de um lugar de origem do pensamento do Ser no qual imperava uma vontade que teria se manifestado no começo da filosofia grega. Heidegger parece ter acreditado que poderia "ultrapassar" ou pelo menos deter a fúria desenfreada da Técnica mediante um retorno à origem grega da filosofia e da ciência. O lugar de origem do pensamento do Ser não seria mais instaurado nos limites da existência finita do Dasein, mas por uma vontade que teria se manifestado no começo (Anfang) da filosofia grega. Tratava-se, portanto, não de estar à mercê de uma Vontade de Poder que se impõe na fase terminal da metafísica, mas de servir aos poderes mais elevados que teriam se manifestado na grandeza originária da filosofia grega, quando pela primeira vez um povo teve a coragem de colocar a totalidade do ente em questão (Cf. HEIDEGGER, 1997, p. 4). Entretanto, o filósofo não permaneceria por muito tempo nesse caminho de retorno aos gregos, ele reconhece que teria falhado ao não colocar em questão a essência não técnica da técnica moderna e ao não compreender que a Vontade de Potência, que caracteriza a técnica e a ciência moderna, já estava presente na origem da filosofia da grega. A fúria da técnica em dominar e organizar a práxis humana e a natureza já estariam presente no "Tudo é água" de Tales. Já no final dos anos 30, Heidegger perceberá que a exposição à origem não significa necessariamente a submissão à força inicial da filosofia grega. O pensador começa a falar de um apelo que nos advém de uma outra origem, de um pensamento mais inicial que o grego. 
Haveria assim um outro começo do pensamento do ser, diferente do grego e capaz de nos libertar da herança do primeiro começo grego: o domínio planetário da técnica.

Mas seria possível falar de uma "essência" da técnica? Em que sentido essa essência impensada da técnica abrigaria um perigo e ao mesmo tempo aquilo que salva?

\section{A essência não técnica da técnica}

Haveria sentido falar em essência não técnica e impensada da técnica? Reportemos ao texto da famosa conferência pronunciada por Heidegger em 1953 sob o título A pergunta pela Técnica (Die Frage nach der Technik) (Cf. HEIDEGGER, 1958) na tentativa de compreender o fenômeno da técnica para além dos limites de uma concepção antropológico-instrumental e em sua relação com a téchne grega. Heidegger começa sua exposição perguntando pelo ser do instrumento. Em que âmbito algo se desdobra como um meio e como um fim? Ora, observa Heidegger, "onde fins são perseguidos e meios são empregados, onde domina o instrumental, ali impera a causalidade (Ursächlichkeit). (HEIDEGGER, 1958, p. 45). A própria noção de causalidade deve ser esclarecida na indagação pelo ser disso que é o instrumento. 0 termo grego para causalidade é aition ([?]?]?][?]? que significa não apenas mero efetuar, produzir um efeito, mas o estar comprometido, o ser responsável por algo vir à presença e desvelar-se na obra ergon. Esse produzir é uma poiesis que vai além da criação artístico ou técnico-manual e confere toda especificidade à téchne grega em relação à técnica moderna, pois remete à própria physis. A essência da téchne estaria nesse poder desvelar, trazer à presença, o que estabelece uma relação essencial com o fenômeno da verdade enquanto des-velamento (alétheia) do ente em seu ser.

A técnica moderna, assim como a téchne grega, é também uma espécie de des-velamento, mas não no sentido da poiesis que imita a própria physis no seu eterno jogo de criar e destruir. A técnica moderna impõe uma espécie de desvelamento que é um desafiar (Herausfordern), que exige que a natureza se transforme em um estoque de reserva (Bestand) para servir o ciclo infindável da produção-consumo. O inquietante é que esse desvelamento, esse trazer à presença, 
operado pelo poder da técnica moderna nunca será algo realizado pelo homem, ao contrário, o homem é ele também provocado pela técnica, enquanto seu funcionário e primeira e fundamental matéria prima.

O desabrigar imperante na técnica moderna é um desafiar (Herausfordern) que estabelece, para a natureza, a exigência de fornecer energia suscetível de ser extraída e armazenada enquanto tal. Mas o mesmo não vale para os antigos moinhos de vento? Não. Suas hélices giram, na verdade, pelo vento e permanecem imediatamente familiarizadas ao seu soprar. .... Uma região da terra, em contrapartida, é desafiada por causa da demanda de carvão e minérios. A riqueza da terra desabriga-se agora como reserva mineral de carvão, o solo como espaço de depósitos minerais. De outro modo se mostrava o campo que o camponês antigamente preparava, onde preparar ainda significava: cuidar e guardar. (Cf. HEIDEGGER, 1958, p. 57)

Todo campo hoje põe/requer (stellt) a natureza como um fundo de reservas disponível. "O campo é agora uma indústria de alimentação motorizada. $O$ ar é posto para o fornecimento de nitrogênio, o solo para o fornecimento de minérios, $o$ minério, por exemplo, para o fornecimento de urânio, este para a produção de energia atômica, que pode ser associada ao emprego pacífico ou à destruição". (Cf. HEIDEGGER, 1958, p. 57). A técnica moderna requerer/requisita/intima e desafia as energias naturais na forma de um estímulo/fomento (Fördern). Um fomento que impele sempre adiante para o máximo de proveito com o mínimo de despesas. Nesse sentido, aquilo que é desvelado pela técnica é a mera subsistência (Bestand) disponível ao cálculo. (Cf. HEIDEGGER, 1958, p. 58). O explorar, transformar, armazenar e distribuir são modos de desvelar da técnica moderna. Um desvelamento que nos mostra o ente, as coisas, como algo meramente subsistente (Bestand) disponível ao cálculo. (Cf. HEIDEGGER, 1958, p. 22). E o homem é aquele que torna possível esse desafio que a técnica moderna lança à natureza. Mas “... apenas quando, por seu lado, o homem for desafiado a desafiar as energias naturais pode acontecer este desabrigar que requer algo." (Cf. HEIDEGGER, 1958, p. 65). E devido ao fato de ser desafiado mais originariamente do que a própria natureza, o homem nunca será uma mera subsistência. Na conferência Princípio de Identidade (1957), Heidegger chamará nossa atenção para esse poder desafiador da técnica moderna, cujo alvo em nossa época não 
é apenas o homem, mas tudo o que é, natureza e história, sob o ponto de vista de seu ser.

Toda nossa existência sente-se em toda parte - uma vez por diversão outra vez por necessidade, ou incitada ou forçada -, provocada a se dedicar ao planejamento e cálculo de tudo. O que fala nesta provocação? Emana ela apenas de um arbitrário capricho do homem? Ou nos aborda nisso já o ente mesmo, e justamente de tal modo que nos interpela na perspectiva de sua planificabilidade e calculabilidade? Então até mesmo o ser estaria sendo provocado a manifestar o ente no horizonte de sua calculabilidade? Efetivamente. E não apenas isto. Na mesma medida que o ser, o homem é provocado, quer dizer, chamado à razão para armazenar o ente que aborda como o estoque de reserva para seu planificar e calcular e a realizar a exploração indefinidamente. (HEIDEGGER, 1987b, p. 184)

O fato é que também a técnica moderna, assim como a téchne grega, produz um des-velamento, um trazer a presença. Contudo, a téchne, como capacidade para produzir utensílios e obras de arte, promovia a aparição de obras que não implicavam uma atitude arrogante e agressiva diante da natureza (physis), mas uma relação de harmonia com o velamento e des-ocultamento constitutivos da physis. Por outro lado, a técnica moderna promove e fomenta um tipo de desvelamento dos entes que não se daria sob o modo da conveniência, mas sobre o modo do desafio, da provocação, do ataque.

Mas, voltemos a perguntar, qual seria o caráter do pensamento apto a ultrapassar esse processo de objetificação no momento de sua consumação na Era da técnica, instaurando um novo começo em nossa história de povo Ocidental?

Tal questão exige que lancemos um olhar para a essência da técnica que não tem nada de técnico. A técnica seria um princípio metafísico que impõe uma determinada concepção da essência do Ser (visto como o meramente disponível, o subsistente) e da verdade como algo fundado na certeza de si de uma suposta subjetividade incondicionada (Descartes, Kant, Nietzsche) e cuja essência estaria na adaequatio.

No reino planetário da técnica e sob a hegemonia do pensamento calculador os entes, as coisas, são expostos em sua 
disponibilidade a toda forma de planificação e maquinação (Machenschft). Entretanto, justamente por sua essência não ter nada de técnico, a técnica não pode ser pensada pela ciência e pelo pensamento calculador. Em Que é metafísica? (1929), Heidegger já considerava que de nenhum modo é o pensamento exato o pensamento mais rigoroso. "O pensamento exato prende-se unicamente ao cálculo do ente... O cálculo não admite outra coisa que o enumerável. Cada coisa é apenas aquilo que se pode enumerar." (HEIDEGGER, 1987e, p. 50). Em O fim da filosofia e a tarefa do pensamento (1966), Heidegger considera que o cálculo, além de possuir uma essência destrutiva, confere uma ilusória produtividade ao pensamento calculador, enquanto reduz tudo à condição de objeto/mercadoria produzida e consumida segundo as leis de um Deus onipotente e onisciente, o mercado global.

É importante ressaltar que a técnica em seu domínio planetário não se resume em artefatos eletrônicos e a esse amontoado de máquinas instaladas nos parques industriais ou presentes em nossos lares. "Estamos, contudo, entregues da pior maneira à Técnica quando a consideramos como uma coisa neutra, pois tal representação, que hoje em dia goza de um prestígio todo especial, deixa- nos completamente cegos em face da essência da técnica." (HEIDEGGER, 1958, p. 42). Portanto, quando Heidegger pergunta pela essência da técnica, ele não se satisfaz com a afirmação que a técnica seja um mero meio para certos fins, sendo, pois, um negócio, um fazer do homem. Para essa visão antropológica instrumental, a técnica não passaria de um instrumento a serviço do homem e de sua vontade ávida em controlar a totalidade dos entes. Isso pressuporia que a técnica é um instrumento que persegue fins colocados pelo próprio homem que supostamente teria o controle do desenvolvimento tecnológico. 0 homem seria então mestre-sujeito da técnica e capaz de controlar a natureza e a sociedade por meio dela. Paradoxalmente, observa 
Heidegger, esse querer-dominar torna-se tão mais urgente quanto mais a técnica ameaça escapar ao controle humano (Cf. HEIDEGGER, 1958, p. 44).

É comum considerar que a diferença da técnica moderna em relação a outras técnicas anteriores estaria no fato dela se apoiar no projeto matemático de natureza da ciência moderna. Mas a questão decisiva para Heidegger continua sendo: "De que essência é a técnica moderna para que incorra no emprego da ciência exata da natureza? Também ela é um desabrigar. Somente quando deixamos repousar o olhar sobre este traço fundamental, mostrar-se-á a nós a novidade da técnica moderna" (Cf. HEIDEGGER, 1958, p. 57).

Mas onde estaria a essência desse fenômeno que hoje atinge dimensões planetárias, afinal qual a essência da técnica? Ou melhor, haveria uma essência da técnica? Heidegger recorreu à palavra Gestel/ ${ }^{3}$ (armação/arrazoamento/dispositivo) para designar a essência da técnica moderna. No Ge-stell (Armação/dispositivo/instalação) reúne-se o colocar/armar que intima e desafia o homem a desvelar a realidade como mera subsistência disponível ao cálculo. (Cf. HEIDEGGER, 1958, p. 64). O Ge-stell não é nada de técnico, nada de tipo maquinal, mas o modo segundo o qual a realidade se desabriga/desvela como subsistência (Bestand), ou seja, como estoque de reserva disponível ao pensamento calculador. Heidegger ressalta que esse desvelamento não é obra humana, mas um acontecimento na história do Ser. (Cf. HEIDEGGER, 1958).

Por ser um destino - a manifestação epocal do ser como técnica planetária não se deixa jamais controlar por um fazer humano, isso não significa que a técnica seja uma fatalidade que nos aprisiona numa coação apática. “... se nos abrimos propriamente à essência da técnica, encontrar-nos-emos inesperadamente estabelecidos numa exigência libertadora" (HEIDEGGER, 1958, p. 75). Para tanto, devemos aprender a ver no perigo que nos é destinado na essência da técnica o

\footnotetext{
${ }^{3}$ Gestell -Na língua corrente a palavra significa: uma espécie de cavalete de pau, um estrado, um suporte, um andaime, um esqueleto, uma montagen. Contudo, Heidegger confere uma nova dimensão à significação corrente dessa palavra, ao afirmar que o Gestell é a essência da técnica. A essência do Gestell é reunir nele mesmo todas as possibilidades do requerer/intimar/requisar (Stellen) .."
} 
nascimento daquilo que salva, ou seja, devemos aprender a ver o perigo como perigo isso já é o começo da salvação. Mas qual seria a natureza desse perigo?

\section{O perigo na essência da técnica}

Esse mesmo homem que se arroga ser o senhor e mestre da natureza e dominador da Terra desconhece tanto a essência da técnica quanto o perigo (Gefahr) que ela abriga. O perigo aqui não ameaça apenas o homem empírico, mas sua essência. A ameaça de uma instalação indefinida e total da técnica por toda terra representa, para Heidegger, uma perspectiva muito mais sinistra, uma ameaça de morte maior que toda ameaça de destruição física da humanidade por uma guerra nuclear. E a possibilidade de ultrapassamento da técnica dependeria de uma mudança de atitude em relação a ela e um novo olhar lançado em sua essência, vislumbrando o perigo que aí se aloja. Entretanto, esse perigo não deveria conduzir a uma condenação moral da mesma ou a sua pura e, simples negação como algo demoníaco.

O perigo não é verdadeiramente, senão quando o homem o olha, senão quando o pensamento saiba reconhecer, além dos aparentes progressos ou aperfeiçoamentos da realidade, uma ameaça à própria essência humana. Nós olhamos para o perigo, e nesse olhar vislumbramos ao mesmo tempo aquilo que salva. É o próprio poeta Hölderlin quem diz: onde o perigo aparece como perigo, é também já nascido aquilo que salva. (Cf. HEIDEGGER, 1987b, p. 36). Não devemos esperar que onde exista o perigo também possamos imediatamente encontrar aquilo que salva. 0 perigo é ele mesmo isto que salva, se ele é visto como perigo. O que se torna difícil já que esse perigo aparece hoje com os sinais do progresso e do bem estar.

O fato é que toda salvação que não provenha mesmo do perigo, não livrará o homem da ameaça que Ihe advém como destino. Enquanto o homem não aprender a olhar a essência da técnica e ver que ali se aloja não apenas o perigo, mas também o que salva, ele continuará sendo a "besta do trabalho" que abandonada à vertigem de suas fabricações, dilacera a si mesma, caindo na mais extrema indigência e penúria. 0 homem é transformado numa besta do trabalho, o que atesta sua cegueira diante do perigo que o acossa. Ele se ilude de que é o sujeito e possuidor de uma vontade que devasta a terra e uniformiza as coisas pelo cálculo. O inquietante é que em todo esse 
processo de instalação planetária da técnica mediante os mecanismos de controle e de cálculo, todas as coisas são transformadas em objetos meramente subsistentes (Bestand). O homem é ele mesmo transformado na primeira e fundamental matéria prima num processo em que todos os setores do ente são submetidos a ordem e a segurança necessárias para um maior aproveitamento possível dos recursos disponíveis. Não podemos descartar a possibilidade de que em um futuro próximo surjam fábricas para repor essa matéria-prima fundamental que é o homem. (Cf. HEIDEGGER, 1958)

A técnica torna-se, assim, a organização da penúria no âmbito de uma fabricação em massa. O princípio da produtividade faz com que a totalidade do ente seja mergulhada numa ausência de diferença que aniquila qualquer hierarquia. Nesse mundo uniformizado pelo calculo, o homem perdeu sua relação com a terra e as coisas. Isso acontece não devido a um desenraizamento acidental nas sociedades industriais que criam-simulam mundos e realidades cada vez mais homogeneizadas e artificializadas. É o projeto tecnológico que exclui a existência mesma de qualquer coisa como uma terra, ou seja, algo não objetivável, não disponível ao poder desafiador da técnica. (Cf. HEIDEGGER, 1958).

O importante é termos consciência de que nenhuma liberação, transformação, acumulação e direção pacíficas das energias naturais poderá superar o domínio planetário da técnica se não houver uma mudança na própria relação do homem com seu ser e o ser das coisas, mas infelizmente isso não depende da vontade humana. (Cf. HEIDEGGER 1997, p. 271-2)

Mas haveria um pensamento apto a superar esse domínio devastador da técnica?

\section{O pensar originário}

Um pensamento apto a ultrapassar o domínio planetário da técnica deve perguntar: quais seriam o solo e o fundamento para um arraigo vindouro do homem na terra inóspita do cálculo? Assim, o que tal pensar busca é o mais próximo. Entretanto, para nós, homens de uma época que aboliu todas as distâncias, o caminho 
ao mais próximo é sempre o mais árduo (HEIDEGGER, 1976, p. 25). Reportando à experiência do ser no dizer e no pensar dos pensadores e poetas gregos anteriores à viragem platônica, Heidegger considera como pensamento fundamental aquele cujos pensamentos não apenas calculam, mas são determinados pelo outro do ente, ou seja, o próprio ser. Em vez de calcular com o ente e sobre o ente, o pensamento originário se dissipa no ser pela verdade do ser, respondendo ao seu apelo. No pensar originário, o ser tem acesso à sua morada - a linguagem, a casa do ser onde mora o homem. Pensadores e poetas são os guardiões dessa habitação. Nessa guarda eles consumam a manifestação do ser, na medida em que pensam e dizem o que o ser lhes enviou. Entretanto, uma autêntica experiência da essência desse pensar originário, que implicaria sua própria realização, exigiria nossa libertação da interpretação técnica do pensar que perpassa toda história da filosofia ocidental.

Na conferência Ciência e Meditação (1953), Heidegger retoma a questão da possibilidade de um pensamento originário capaz de ultrapassar a metafísica e a concepção cibernética do real e da linguagem. Tal pensamento certamente não nos conduzirá a nenhum outro lugar, senão àquele onde desde sempre já moramos (HEIDEGGER, 1954, GA 07, p. 48). O pensamento originário seria, portanto, fundamentalmente a experiência de uma dimensão ante predicativa, que Heidegger chama de clareira (Lichtung) - uma espécie de iluminação, mais existente que o próprio existente e que é condição de possibilidade de todo dar-se. Esse pensar originário aproxima-se das coisas não através do olhar objetivante que abole qualquer distância ou proximidade no espaço puro da geometria. Esse pensar sabe que tudo que é presente traz em si uma certa reserva, uma vez que a clareira (Lichtung) em que está o existente é em si mesma também ocultação, que se oculta e dissimula a si mesma. É justamente ao tentar experienciar esse jogo de retraimento do ser que se dissimula e oculta seu próprio retraimento naquilo que se presentifica (o ente) que o pensar originário consuma a relação do ser com a essência do homem. E somente mostrando isso que se retira e se subtrai, nós conseguiremos ser nós mesmos. Nós somos na medida em que indicamos isso que se oculta. 
Para uma época indigente como a nossa, que se compraz em sua própria indigência, Heidegger receita mais pensamento e menos filosofia. Um pensamento que não seja mais filosofia. Mas onde o pensamento originário encontraria sua medida e sua lei, se ele não se deixa medir por seus possíveis efeitos no mundo dos entes? Segundo Heidegger, a tarefa que estaria reservada a esse pensamento dócil ao apelo da verdade do Ser possui apenas um caráter preparatório. Daí esse pensamento satisfaz-se em despertar apenas uma disponibilidade no homem para uma possibilidade cujos contornos permanecem indefinidos e o advento incerto.

\section{Para não concluir...}

A leitura heideggeriana do fenômeno da técnica leva-nos à seguinte constatação: se é certo que a técnica plenifica o niilismo, o desenraizamento do homem, o desencanto da Natureza, o esquecimento do Ser e a fuga dos deuses; por outro lado, ela é também o âmbito no qual emerge a possibilidade de um retorno ao ser das coisas e do próprio homem a partir de um novo começo. Um novo começo que inauguraria uma época na qual nossas relações com as coisas não se fariam apenas pela mediação de dispositivos técnicos. Essa constatação traria consigo uma série de implicações que seria conveniente ressaltar nessa conclusão.

Apesar de toda a parafernália tecnológica disponível para o controle e planejamento biossocial, permanece incerto, por exemplo, se a civilização mundial será em breve subitamente destruída ou se cristalizará numa longa duração, que não resida em algo permanente, mas que se instale, muito ao contrário, na mudança contínua em que o novo é substituído pelo mais novo. Isso não significa que devemos nos deixar levar por algum ativismo ou qualquer espécie de revolta diante da técnica, sob pena de cairmos na armadilha do pensamento calculador. Nenhuma ação jamais conseguirá provocar qualquer mudança na essência da técnica, e muito menos na essência do ser do ente e do homem. Não temos nada a fazer para evitar ou amenizar os efeitos devastadores do domínio planetário da técnica, só nos resta esperar. Uma espera que não significa resignação, mas uma espécie de serenidade (Gelassenheit) que nos permita ver o perigo na essência da técnica. 
Nesse sentido, nenhuma instância ou doutrina de caráter ético-político poderá promover esse retorno a um contato originário com as coisas e com nós mesmos. Nenhuma vontade humana, individual ou coletiva, poderá controlar e direcionar esse domínio planetário da técnica. Isso porque a técnica não é um mero meio para certos fins postos pelo homem. Ora, a técnica não é um puro fazer humano, nem é mesmo o homem o agente principal desse acontecimento. Pelo contrário, é o homem a primeira vítima, o primeiro a ser explorado e provocado por ela, aquele que, mais que qualquer outro ente, converte-se na primeira e fundamental matéria-prima.

Heidegger reconhece que no mundo de hoje não podemos mais renunciar à técnica e à ciência moderna. Por outro lado, o filósofo tem plena consciência que esse domínio planetário da técnica representa um perigo para a essência do homem. 0 pensador insiste em dizer que o pensamento precursor não quer nem pode predizer um futuro, mas procura apenas ditar para o presente algo que há muito, exatamente no começo da Filosofia, já Ihe foi dito, e que, entretanto, não foi propriamente pensado - que todo ente é no ser. Portanto, o papel do autêntico pensador do Ser é desviar-se do alarido e da inquietação fervilhante do mundo da técnica e penetrar nessas sendas perdidas, situando-se em perspectivas que mostrem que a técnica não se basta.

A questão que se colocaria então seria: como preparar novamente o mundo para que o homem possa novamente nele construir, morar e pensar? Para Heidegger, a filosofia não pode produzir um efeito imediato que possa fazer mudar o estado presente do mundo. Isto não vale apenas para a Filosofia, mas para todas as preocupações e aspirações por parte do homem. Não devemos nos deixar levar por nenhum ativismo ou qualquer espécie de revolta diante da técnica. Nenhuma ação jamais conseguirá provocar qualquer mudança na essência da técnica, e muito menos na essência do Ser e do homem. Não temos nada a fazer para evitar ou amenizar os efeitos devastadores do domínio planetário da técnica, só nos resta esperar. Uma espera que não significa submissão ou resignação. Infelizmente, nenhuma iniciativa humana poderá promover essa uma reviravolta (Kehre) capaz de propiciar a superação 
do domínio planetário da técnica, instaurando um novo modo de ser e pensar do homem.

Antes de mais nada é necessário que o homem perceba, para além dos aparentes progressos ou aperfeiçoamentos da realidade, que há um perigo na essência da técnica que é uma ameaça à própria essência humana. Devemos olhar para o perigo e ver ao mesmo tempo aquilo que salva. O poeta nos diz onde o perigo aparece como perigo, é também já nascido aquilo que salva. Mas o que significa salvar (Retten) no dizer do poeta?

\begin{abstract}
"Salvar é: recolher na essência, para assim primeiramente trazer a essência a seu autêntico aparecer. Se a essência da técnica, o Gestell, é o extremo perigo e se a palavra de Hölderlin diz ao mesmo tempo algo de verdadeiro, então o domínio do Ge-stell não pode se esgotar em apenas obstruir todo brilhar de cada desabrigar e todo aparecer da verdade. Então, a essência da técnica deve antes justamente abrigar em si o crescimento daquilo que salva. (HEIDEGGER, 1958, p. 80)
\end{abstract}

O inquietante é que o "... fazer humano nunca pode imediatamente ir ao encontro desse perigo. A empresa humana nunca pode sozinha banir este perigo. Mas, a meditação humana pode refletir sobre o fato de que tudo o que salva necessita de uma essência superior a do perigo, embora ao mesmo tempo seja a ela aparentada." (HEIDEGGER, 1958, p. 45-46). Mas como uma tão extrema indigência, que não somente se ignora, mas que se manifesta com os sinais do progresso e do bem estar, poderá ser superada? O pior é que o perigo dissimula muito bem sua própria essência.

Infelizmente, o barulho das máquinas torna o homem surdo ao apelo de seu próprio ser e do ser das coisas reduzidas à condição de objeto disponível ao calculo. " $A$ besta do trabalho é abandonada à vertigem de suas fabricações, afim de que ela se dilacere ela mesma, que ela se destrua e caia na nulidade do nada. (Cf. HEIDEGGER, 1958, p. 83). Será que vale a pena vender tão caro nossa liberdade por todo esse aparato de segurança e um certo conforto material, que só nos tornam mais indolentes e alienados em relação às nossas mais autênticas necessidades e capacidades? Em último caso, cabe a nós decidir se da noite desse tempo de penúria e 
indigência surgirá uma nova aurora do pensamento do ser. Enquanto isso, como disse certa fez um grande filósofo: "deserto cresce..." (Nietzsche).

\section{Referências}

JÜNGER, Ernst. Le Travailleur. Tradução e apresentação de Julien Hervier, Christian Bourgois Éditeur, Paris, 1989.

HAAR, M. Le tournant de la Détresse. Cahier de L'HERNE - Heidegger. Paris: Ed. L'Herne, 1983, p. 331-358.

HABERMAS, J. O Discurso Filosófico da modernidade. Trad. Ana Maria Bernardo et ali. Lisboa: Pub. Dom Quixote, 1990, pp. 131-156.

HEIDEGGER, Martin. Ser e Tempo. Trad. Marcia S. Cavalcanti. 2a. ed. Petrópolis: Ed. Vozes, 1988.

. Sobre o Humanismo. In: Conferências e Escritos Filosóficos. Trad.

Ernildo Stein. São Paulo: Abril cultural, 1987a.

- Identidade e Diferença. In: Conferências e Escritos Filosóficos.

Trad. Ernildo Stein. São Paulo: Abril cultural, 1987b.

- Fim da Filosofia e a tarefa do pensamento. In: Conferências e

Escritos Filosóficos. Trad. Ernildo Stein. São Paulo: Abril cultural, 1987c.

- Sobre a essência do Fundamento. In: Conferências e Escritos

Filosóficos. Trad. E. Stein. SP: Abril Cultural, 1987d

. Que é Metafísica? In: Conferências e Escritos Filosóficos. Trad.

E.Stein. SP: Abril Cultural, 1987e.

. A auto-afirmação da Universidade alemã. Trad. Fausto Castilho.

Curitiba: Secretaria de Estado da Cultura, 1997.

. Hölderlin et L'essence de la poésie. In: Approche de Hölderlin.

Trad. Par H. Corbin. Paris: Gallimard, 1962

Caminos del Bosque. Madrid, 1997.

Tempo Brasileiro, 1969.

Introdução à Metafísica. Trad. Emmanuel C. Leão. Rio de Janeiro:

Alegre: Globo, 1969b.

Da experiência do Pensar. Maria do Carmo T. Miranda. Porto

. Essais et Conférences. Trad. par A . Preau. Paris: Gallimard, 1958.

Qu'est-ce que la philosophie? In: Questions II. Trad. par K. Axelos

et J. Beaufret. Paris: Gallimard, 1968.

. Qu'est-ce que'une chose? Trad. par Rebout et alii Paris: Gallimard, 1971.

Gallimard, 1976.

Le tournant. In: Questions IV. Trad. par J. Beafret et alii. Paris:

LOPARIC, Z. Heidegger e a pergunta pela Técnica. Cad. de História e Filosofia da Ciência. Série 3, v. 6, n. 2, p. 107-138, jul-dez. 1996

NIETZSCHE, Friedrich. Assim falou Zaratustra. Rio de Janeiro: Ed. Civilização Brasileiro, 1983, p. 145-148.

NUNES, Benedito. Passagem ao Poético. Filosofia e Poesia em Heidegger. São Paulo: Ática, 1992. 
PÖOGELER, Otto. Le pensée de Heidegger, un cheminement vers l'être. Paris: Aubier, Ed. Montaigne, 1967.

WAHL, Jean. La pensée de Heidegger et la poésie de Hölderlin. Paris; Centre de Documentation Universitaire. (Sem dados).

Faculdade de Educação - UFG Prof. Adjunto IV - Área de Filosofia Doutor em Filosofia (UNICAMP). E-mail: wanderleyf4@gmail.com 